\title{
MODELING THE INFLUENCE OF INTERACTION LAYER FORMATION ON THERMAL CONDUCTIVITY OF U-Mo DISPERSION FUEL
}

\author{
Douglas E. Burkes ${ }^{\mathrm{a}}$, Andrew M. Casella ${ }^{\mathrm{a}}$ and Tanja K. Huber ${ }^{\mathrm{b}}$ \\ ${ }^{a}$ Pacific Northwest National Laboratory, Nuclear Engineering and Analysis Group \\ P.O. Box 999 MSIN K8-34, Richland, WA, USA 99352 \\ ${ }^{\mathrm{b}}$ Technische Universität München, Forschungs-Neutronenquelle Heinz Maier-Leibnitz \\ Lichtenbergstr. 1, D-85748, Garching, Germany
}

Corresponding Author Contact Information

Dr. Douglas E. Burkes

Nuclear Engineering \& Analysis Group

Pacific Northwest National Laboratory

P.O. Box 999, MSIN K8-34

Richland, WA, U. S. A. 99352

Phone 1 (509) 3724152

Fax 1 (509) 3752610

E-mail Douglas.Burkes@pnnl.gov

Submitted to Journal of Alloys and Compounds

June 2014

Revised August 2014

This manuscript has not been published elsewhere and has not been submitted simultaneously for publication elsewhere. 


\begin{abstract}
The Global Threat Reduction Initiative Program continues to develop existing and new test reactor fuels to achieve the maximum attainable uranium loadings to support the conversion of a number of the world's remaining high-enriched uranium fueled reactors to low-enriched uranium fuel. Currently, the program is focused on assisting with the development and qualification of a fuel design that consists of a uranium-molybdenum (U-Mo) alloy dispersed in an aluminum matrix. Thermal conductivity is an important consideration in determining the operational temperature of the fuel and can be influenced by interaction layer formation between the dispersed phase and matrix, porosity that forms during fabrication of the fuel plates or rods, and upon the concentration of the dispersed phase within the matrix. This paper develops and validates a simple model to study the influence of interaction layer formation, dispersed particle size, and volume fraction of dispersed phase in the matrix on the effective conductivity of the composite. The model shows excellent agreement with results previously presented in the literature. In particular, the thermal conductivity of the interaction layer does not appear to be as important in determining the effective conductivity of the composite, while formation of the interaction layer and subsequent consumption of the matrix reveals a rather significant effect. The effective thermal conductivity of the composite can be influenced by the dispersed particle distribution by minimizing interaction layer formation and preserving the higher thermal conductivity matrix.
\end{abstract}


KEYWORDS: composite materials; nuclear reactor materials; thermodynamic properties; thermal analysis

\section{INTRODUCTION}

A significant number of the world's remaining high performance research reactors (HPRR) still utilize high-enriched uranium (HEU) to provide the high specific powers and neutron fluxes that make these reactors unique. Use of HEU can also result in extended residence time of the fuel in the core, higher specific reactivity, and, as a result, somewhat lower fuel cycle costs. With expanded interest in nuclear research, testing, energy, and medical isotopes; concerns over commerce of HEU and improved proliferation resistance of fuels and fuel cycles concomitantly increase. One of the main objectives of the Global Threat Reduction Initiative Program (formerly referred to as the Reduced Enrichment for Research and Test Reactors Program) is to develop existing and new plate-type and rod-type research and test reactor fuels to achieve maximum attainable uranium loadings. By increasing the uranium loading, enrichment reduction is possible to less than $20 \%$ (defined as low enriched uranium (LEU)) without significant penalties in safety, performance, or fuel cycle cost [1]. An enrichment level of less than $20 \%$ has been recommended as the preferred enrichment level for research reactor fuels in order to minimize overall proliferation risks $[2,3]$.

Dispersion type fuels, commonly used in research and test reactors, consist of a fissile isotope bearing material that is uniformly distributed in a nonfissile material or diluent matrix. Dispersion fuel designs are unique and attractive for two primary reasons. First, fission-product damage can be localized, thereby minimizing damage to a structural matrix material. Second, use of a dispersion fuel design permits an increased choice of fuel systems and matrix materials that may otherwise normally be metallurgically incompatible [4]. The choice of a particular fuel system is guided and informed by dimensional stability under irradiation, thermal and physical properties, and compatibility of the dispersed phase with the matrix material at both fabrication and irradiation temperatures. The choice of matrix materials is principally guided and informed by physical and chemical properties. In large part, the properties of the matrix material will dominate the behavior of the fuel design itself such that the matrix should be ductile, insensitive to neutron damage, retain fission products, possess adequate corrosion resistance, have a comparable coefficient of thermal expansion to the cladding material, and possess high thermal conductivity. The GTRI/RERTR program has assisted in the development of higher loading $\mathrm{UAl}_{\mathrm{x}}$ and $\mathrm{U}_{3} \mathrm{O}_{8}$ fuels that enable a reduction in the uranium enrichment. Furthermore, the program assisted the global effort to develop and qualify a new $\mathrm{U}_{3} \mathrm{Si}_{2}$ fuel type that is now used in a number of lower power research reactors worldwide. The program has now focused efforts to assist with the development and qualification of a fuel type with an even higher loading that consists of a uraniummolybdenum (U-Mo) alloy. This alloy offers the ability to increase the uranium loading significantly, thereby allowing reduced enrichment and permitting the conversion of some of the worlds most powerful research and test reactors from HEU to LEU.

Thermal conductivity is an important consideration in determining the operational temperature of the fuel plate. In the case of dispersion fuels, thermal conductivity is 
primarily dependent upon the thermal conductivity of the matrix material itself, porosity that forms during fabrication of the fuel plates or rods, and upon the concentration of the dispersed phase. However, interactions between the dispersed phase and matrix as a result of interdiffusion can also play a role in thermal conductivity degradation that, in turn, could affect the operational temperature of the fuel. In the case of U-Mo dispersion fuels, the interaction layer (IL) that forms between the dispersed particles and the matrix reportedly consists of multiple phases and may initially be formed during fabrication and/or enhanced during irradiation [5]. The IL may possess a thermal conductivity that affects fuel performance [6], although direct measurements of the IL have not been performed to the authors' knowledge. As a result, the thermal conductivity of the IL is often assigned a value lower than that of the dispersed particle itself, with assumptions as low as $5.5 \mathrm{~W} \cdot \mathrm{m}^{-1} \cdot \mathrm{K}^{-1}$ [7] being used. The purpose of the present paper is to develop a simple model that predicts the thermal conductivity of dispersion type fuel and to investigate the sensitivity of this property to parameters such as volume fraction (loading), particle size, and IL thickness. The model developed here is validated against measurements performed on unirradiated U-Mo dispersion fuel samples.

\section{CALCULATION}

The effective thermal conductivity of a dispersed composite can be determined using a variety of practical models. The effectiveness of a particular model is dependent upon the assumptions for which the theory has been derived. Three of the most common models to calculate effective thermal conductivity of a dispersed composite are: (i) the Maxwell model [8] shown in Equation 1, (ii) the Bruggeman model [9] shown in Equation 2, and (iii) the Hsu model [10] shown in Equation 3.

$$
\begin{aligned}
& \lambda_{e}=\lambda_{m}\left[\frac{\lambda_{d}+2 \lambda_{m}+2 v_{d}\left(\lambda_{d}-\lambda_{m}\right)}{\lambda_{d}+2 \lambda_{m}-v_{d}\left(\lambda_{d}-\lambda_{m}\right)}\right] \\
& 1-v_{d}=\frac{\lambda_{d}-\lambda_{e}}{\lambda_{d}-\lambda_{m}}\left(\frac{\lambda_{m}}{\lambda_{e}}\right)^{\frac{1}{(x+1)}} \\
& \{1-F(e)\} \lambda_{e}^{2}+\left\{\lambda_{d}\left[F(e)-v_{d}\right]+\lambda_{m}\left[F(e)-v_{m}\right]\right\} \lambda_{e}-\lambda_{d} \lambda_{m} F(e)=0
\end{aligned}
$$

In Equations 1 through 3, $\lambda$ is thermal conductivity, $v$ is volume fraction, $x$ is a factor designed to account for the shape of inclusions ( $x=2$ for spheres), $F(e)$ is a function of the eccentricity of the dispersed phase and is designed to take into account the shape and orientation of the phase $(F(e)=1 / 3$ for spheres), and the subscripts $e, m$, and $d$ represent the effective composite, matrix, and dispersed phase, respectively.

The composite thermal conductivity was calculated for a dispersion type fuel that consisted of spherical U-10Mo particles dispersed in an aluminum matrix using each of the models described above. Volume fractions of 10, 30, 40, and 50\% were evaluated and Equation 4 was used to determine the thermal conductivity of the U-10Mo particles [11] where $\lambda$ is in $\mathrm{W} \cdot \mathrm{m}^{-1} \cdot \mathrm{K}^{-1}$ and $T$ is in $\mathrm{K}$. Values reported in Reference 12 were used for the thermal conductivity of the matrix as a function of temperature. Predicted values were compared with experimental measurements performed by Lee $e t$ al. [13]. The 
experimental composites were reported to be near fully dense, and therefore no correction was applied for porosity. Further, the experimental composites consisted of U-10Mo dispersed in an aluminum alloy (AA) 1060 matrix without cladding. Thermal conductivity data of AA1060 was not available, but was assumed to be similar to aluminum. The uncertainty associated with the experimental thermal conductivity data was not explicitly reported, but is estimated to be within the uncertainty associated with the experiment. A scatter plot comparing the measurements and predictions is provided in Figure 1.

$$
\lambda_{U-10 M o}=0.606+3.51 \times 10^{-2} * T
$$

The thermal conductivity of the composite clearly decreases with increased volume fractions of U-Mo fuel dispersed in the aluminum alloy (AA) 1060 matrix. In addition, within each set of fuel volume fractions, the thermal conductivity increases slightly with increasing temperature on account of the higher thermal conductivity with increased temperature for both the U-10Mo fuel and AA1060 matrix. For low volume fractions, e.g., $10 \mathrm{vol} \%$, the three models yield nearly identical results that are comparable to the measured composite thermal conductivities. However, as the volume fraction is increased beyond $10 \mathrm{vol} \%$ to $30 \mathrm{vol} \%$, the Maxwell and Bruggeman predictions begin to deviate significantly from the measured values, indicated by data points being above the black line. A fundamental assumption in the Maxwell theory is that the concentration of the dispersed phase is low enough that the particles remain far enough apart so as not to interact with one another. The Bruggeman theory neglects interparticle interactions in a similar manner, and therefore both of these approximations are only valid for dilute volume fractions. At $30 \mathrm{vol} \%$, it is apparent that interparticle interactions are playing a significant role in the thermal conductivity of the composite, as both the Maxwell and Bruggeman models over predict the composite thermal conductivity. The Hsu model does not assume a continuous matrix, and therefore can be applied in situations where the matrix and dispersed phases cluster and form agglomerates within the composite. This model shows acceptable agreement with the measured values, even for high volume fractions of fuel, and will therefore be used throughout the remainder of this paper.

\subsection{Influence of interaction layer formation}

It is known that interaction layers, consisting of a mixture of intermetallic compounds, form between U-Mo particles and the aluminum alloy matrix [5]. These interaction layers may be formed during either fabrication or irradiation. If interaction layers are formed during fabrication, they may be further enhanced during irradiation. While thermal conductivity of the interaction layer that forms between the U-Mo particles and the aluminum alloy matrix has not been measured directly, it is often assumed to have a value lower than that of the U-Mo particles. The amount of fuel and/or matrix that is consumed as a result of interaction layer formation is equally important. Thermal conductivity measurements as a function of volume fraction of dispersed phase and temperature have been previously reported $[13,14]$. In one study, samples were subjected to isothermal heat treatments for various times to induce interaction layer formation. An example of thermal conductivities for a composite containing $30 \mathrm{vol} \%$ U-10Mo particles dispersed in an AA1060 matrix as a function of temperature are provided in Figure 2. 
The interaction layer thickness surrounding the particles is included on the figure. Clearly, the presence of an interaction layer results in significant degradation of the composite thermal conductivity.

An expression for the equivalent conductivity of a coated sphere subjected to axial heat flow was required in order to perform sensitivity analyses. Such an expression was obtained following the derivation from heat transport equations and summarized by Badrinarayan and Barlow [15]. This expression is summarized in Equation 5.

$\lambda_{e q}=\frac{R}{\left\{\left(\frac{2 R}{a}\right) \ln \left[\frac{(a R+b)}{(a(R-r)+b)}\right]+\left(\frac{b}{a^{2}}\right) \ln \left[\frac{(a R+b)}{(a(R-r)+b)}\right]+\left(\frac{R-r}{\lambda_{d}}\right)-\left(\frac{r}{a}\right)\right\}}$

where

$a=-\lambda_{I L}$

$b=2(R-r) \lambda_{d}+2 r \lambda_{I L}$

In Equation 5, $R$ is the total particle radius including interaction layer, $r$ is the fuel particle radius, $\lambda_{d}$ is the fuel particle thermal conductivity, and $\lambda_{I L}$ is the interaction layer thermal conductivity.

\section{RESULTS}

The relationships described previously were used to determine the sensitivity of the composite thermal conductivity of dispersion type fuels to the interaction layer volume fraction, interaction layer thermal conductivity, and the dispersed particle size. Results of these analyses and model validation are presented in this section.

\subsection{Sensitivity of interaction layer volume fraction}

The interaction layer must consume the fuel, the matrix, or a mixture of both. The sensitivity of this parameter was investigated using Equations 3 and 5, assuming $60 \mu \mathrm{m}$ diameter U-10Mo fuel particles dispersed in an aluminum matrix, an initial starting fuel volume fraction of $30 \%$, and an interaction layer thickness of $3 \mu \mathrm{m}$ (corresponding to sample U10M_5 in Figure 2). In each case, the interaction layer thermal conductivity was assumed to be the same as the fuel particle thermal conductivity in order to simplify the comparisons. If the interaction layer consumed the fuel particle only, the fuel particle radius would effectively be reduced and the resultant volume fraction of dispersed phase would remain the same at $30 \%$, i.e. no volume change would have occurred. For this case, since the thermal conductivity of the interaction layer is assumed to be the same as the fuel particle, there would be no change in the calculated thermal conductivity of the composite. If the interaction layer consumed the matrix only, the fuel particle radius would effectively remain the same and the resultant volume fraction of fuel plus interaction layer would increase from $30 \%$ to $40 \%$ (equivalent particle radius of $33 \mu \mathrm{m}$ ). If the interaction layer consumes roughly equal amounts of fuel and matrix, the resultant volume fraction of fuel plus interaction layer would increase from $30 \%$ to $34.7 \%$ 
(equivalent particle radius of $31.5 \mu \mathrm{m}$ ). The resultant calculations compared to the experimental measurements are summarized in Figure 3.

It should become immediately apparent from Figure 3 that an increase in the volume fraction of dispersed phase is necessary to influence the type of thermal conductivity degradation created by presence of an interaction layer. In this case, the best agreement is obtained by assuming the interaction layer consumes the aluminum matrix material only, and that the fuel particles retain their original diameter, i.e. $60 \mu \mathrm{m}$. The decrease in composite thermal conductivity is the result of the high conductivity matrix being consumed by a lower thermal conductivity interaction phase. The thermal conductivity of the fuel particle itself is also likely to be lowered, as species (particularly Mo) diffuse from the particle into the aluminum matrix. This observation is contrary to assumptions typically made for U-Mo dispersion fuel, i.e., the IL consumes a portion or the entirety of the fuel particle [16]. In addition, as indicated earlier, numerous out-of-pile diffusion studies indicate that the interaction layer consists mostly of $(\mathrm{U}, \mathrm{Mo}) \mathrm{Al}_{\mathrm{x}}$ intermetallics. In order for this to be possible, more matrix than fuel must be consumed since $\mathrm{UAl}_{\mathrm{x}}$ intermetallics require more matrix atoms per (U,Mo) atom.

\subsection{Sensitivity of interaction layer thermal conductivity}

The sensitivity of interaction layer thermal conductivity on the composite behavior was investigated assuming that the interaction layer consumes the matrix only, based on the results presented in Section 3.1. The thermal conductivity of the interaction layer was assumed to be half the value of the fuel particle, equal to the fuel particle, and twice the value of the fuel particle, with all other assumptions remaining constant. The resultant calculations compared to the experimental measurements are summarized in Figure 4.

Observation of Figure 4 suggests that the composite thermal conductivity is relatively insensitive to the selected value of interaction layer thermal conductivity compared to the volume fraction of the interaction layer itself (see Figure 3). However, assuming the interaction layer thermal conductivity is half the fuel thermal conductivity yields results that are within $3 \%$ of the experimental measurements. Characterization of samples subjected to out-of-pile annealing tests suggest that a mixture of (U,Mo) $\mathrm{Al}_{\mathrm{x}}$ intermetallic compounds comprise the interaction layer, where $x$ can range from 2-4 [5]. Thermal conductivity data of $\mathrm{UAl}_{\mathrm{x}}$ compounds as a function of temperature is scarce, although it has been reported to range from 4.2 to $8.4 \mathrm{~W} \cdot \mathrm{m}^{-1} \cdot \mathrm{K}^{-1}$ at temperatures between 65 and 93 ${ }^{\circ} \mathrm{C}[17,18]$. If the thermal conductivities of the U-10Mo fuel particles at these temperatures are estimated by the correlation of Burkes et al. [11] and divided by two (to represent interaction layer thermal conductivity), then thermal conductivities between 6.2 and $6.7 \mathrm{~W} \cdot \mathrm{m}^{-1} \cdot \mathrm{K}^{-1}$ are obtained. These values are in agreement with the values reported in the literature for $\mathrm{UAl}_{\mathrm{x}}$ compounds at comparable temperatures.

\subsection{Sensitivity of dispersed particle size}

The size of the dispersed particle within the matrix will also have an impact on the observed conductivity of the composite, particularly in the event of interaction layer formation. For a given interaction layer thickness, the volume ratio will be significantly 
higher for a finer particle compared to a coarse particle. Further, more particles will be required to achieve a given volume fraction with a fine particle distribution compared to a distribution consisting of coarser particles. This likely contributes to differences observed between the predictions and measured values, since dispersion fuels typically contain a discrete range of particle sizes. Lee et al. reported the mean diameters of U-Mo particles fabricated by the centrifugal atomization method were approximately $50-70 \mu \mathrm{m}$ [13], although a wide range of U-Mo particle diameters can be produced using this method [19]. The sensitivity of composite thermal conductivity to fuel particle size was evaluated assuming the interaction layer consumes the matrix only (Section 3.1), the interaction layer thickness is $3 \mu \mathrm{m}$, the interaction layer thermal conductivity is half of the fuel particle thermal conductivity (Section 3.2), and all other variables as defined before. The resultant calculations compared to the experimental measurements are summarized in Figure 5. The composite thermal conductivity appears more sensitive to the particle size of the dispersed phase than the thermal conductivity of the interaction layer (see Figure 4). The amount of matrix consumed by a $3 \mu \mathrm{m}$ interaction layer will obviously be lower for coarser particles (e.g. $70 \mu \mathrm{m})$ that results in higher composite conductivity.

\subsection{Model validation}

The models described in Equations 3 and 5 were further validated against all measurements reported by Lee et al. [13,14]. Based on the sensitivity studies, a fuel particle diameter of $60 \mu \mathrm{m}$ was used, the experimentally measured interaction layer (provided in References 13 and 14) was assumed to consume the matrix only, and the interaction layer thermal conductivity was assumed to be half that of the fuel particle. A scatter plot showing the predictions compared to experimental measurements is provided in Figure 6 for composites containing three different initial volume fractions of fuel.

The predicted values are in good agreement with the measured values with the exception of one sample with $40 \mathrm{vol} \%$ of dispersed phase excluding the volume of interaction layer (U10M_8). An interaction layer of $5.86 \mu \mathrm{m}$ was observed to have formed on the fuel particles. Assuming a fuel particle diameter of $60 \mu \mathrm{m}$, this amount of interaction layer formation will result in a significant fraction of the aluminum matrix being consumed, thus resulting in lower predicted values compared to the experimentally measured values. It is likely, although cannot be confirmed based on the conditions reported in the literature, that the particle size distribution was different than the value assumed for this particular sample. A coarser particle diameter, e.g. $80 \mu \mathrm{m}$, would bring the predicted values to closer agreement with the measured values, an example of which was shown in Figure 5.

\section{DISCUSSION}

Interaction layer formation on U-Mo particles, and subsequent consumption of the aluminum matrix, can be influenced through appropriate measures during fabrication. It would appear that interaction layer thickness formation as a result of fabrication should be minimized to allow for the highest thermal conductivity possible at beginning of life. 
However, it has also been reported that an interaction layer forms and continues to increase in thickness during irradiation as a result of fission fragment damage in the interdiffusion zone [20]. Fewer measures are available to control interaction layer formation and growth during irradiation. An empirical correlation to predict interaction layer growth $(Y, \mu \mathrm{m})$ as a function of effective fission density rate $\left(\dot{f}\right.$, fissions $\bullet \mathrm{cm}^{-3} \cdot \mathrm{sec}^{-}$ $\left.{ }^{1}\right)$, irradiation time $(t, \mathrm{sec})$, and temperature $(T, \mathrm{~K})$ is provided in Equation 6 [21,22].

$Y^{2}=2.6 \times 10^{-8} \cdot \dot{f}^{\frac{1}{2}} \cdot t \cdot \exp \left(\frac{-3850}{T}\right)$

Thus, interaction layer formation and subsequent consumption of the high conductivity aluminum matrix is primarily dependent upon fission density (burnup) and temperature, the latter being dependent upon effective thermal conductivity of the fuel. The volume fraction of dispersed phase and interaction layer $\left(v_{(f+Y)}\right)$ can be calculated using Equation 7, where $v_{f}$ is the initial volume fraction of dispersed phase, $V_{D}$ is the volume of a dispersed particle of diameter $D$, and $V_{(D+Y)}$ is the volume of particle and interaction layer combined. Therefore, for a given interaction layer thickness (determined from Equation 6 and dependent upon fission density only), the increase in volume fraction of particle and interaction layer will be slower for coarser particles than for finer particles according to Equation 7.

$v_{(f+Y)}=\frac{v_{f} * V_{(D+Y)}}{V_{D}}$

Modeling studies by Ryu et al. showed that fuel centerline temperature decreased with an increase in the average diameter of U-Mo particles for a given volume fraction of dispersed fuel [6]. The decrease was explained by a reduction in the specific interfacial area available for interaction with coarser particles, and therefore the volume fraction of the lower conductivity interaction layer increased slowly. These studies were conducted using a rod-type geometry and subjected to a specific set of unique irradiation conditions (e.g., coolant temperature, heat flux, etc.). While centerline fuel temperatures were not conducted as part of this work, the sensitivity of effective thermal conductivity to dispersed particle size and interaction layer formation, corresponding to consumption of the aluminum matrix, has been demonstrated and is in agreement with the observations of Ryu et al. Characterization of irradiated samples as part of the KOMO-2 irradiation test showed that samples using a fine U-Mo powder $(38-63 \mu \mathrm{m})$ contained a higher volume fraction of interaction product compared to samples using a coarse U-Mo powder (53-106 $\mu \mathrm{m})$.

Ryu et al. also showed that an increase in the volume fraction of dispersed phase results in higher centerline fuel temperatures for a constant particle size. The Al matrix was exhausted as a result of interaction layer growth after only approximately $10 \%{ }^{235} \mathrm{U}$ burnup with a fuel loading of $8.0 \mathrm{gU} \cdot \mathrm{cm}^{-3}(0.51 \mathrm{vol} \%)$. Williams et al. similarly reported significant reductions in thermal conductivity for increased volume fractions of dispersed phase as a function of interaction layer formation [7]. Thermal conductivity was reduced by half for a composite containing $30 \mathrm{vol} \%$ dispersed phase with approximately $20 \mathrm{vol} \%$ of interaction layer formation. The model described in this paper determined that a fuel 
containing $30 \mathrm{vol} \%$ of $60 \mu \mathrm{m}$ dispersed particles with a $6.26 \mu \mathrm{m}$ interaction layer around the particles is equivalent to a low conductivity dispersed phase of approximately 53 vol\%. If a fuel with $30 \mathrm{vol} \%$ of dispersed particles with no interaction layer is considered, then the predicted thermal conductivity would be $139.2 \mathrm{~W} \cdot \mathrm{m}^{-1} \cdot \mathrm{K}^{-1}$. However, when a $6.26 \mu \mathrm{m}$ thick interaction layer is considered, the model predicts a thermal conductivity of $66.5 \mathrm{~W} \cdot \mathrm{m}^{-1} \cdot \mathrm{K}^{-1}$, which is in excellent agreement with the finite element model developed by Williams et al [7].

Formation of interaction product at the expense of the high thermal conductivity matrix could potentially increase the operational temperature of the fuel, as was demonstrated by the model of Ryu et al. for rod-type fuel. However, the maximum centerline temperature of plate-type dispersion fuels was shown to be insensitive to in-pile degradation of the fuel thermal conductivity by Medvedev, mainly as the result of the very thin fuel meat thickness compared to the cladding [23]. For these calculations, centerline temperature was mainly dependent upon heat flux, and only modest rise in the temperature was noted even with complete consumption of the aluminum matrix. However, the matrix will degrade more rapidly for fuels where interaction layers form at an increased rate, particularly for finer fuel particle distributions. While an increase in centerline temperature may not be expected during routine operation, off-normal events or other unanticipated events, such as excessive growth of oxide on the surface of the cladding during irradiation, could result in much higher temperature excursions due to complete consumption of the aluminum matrix. Furthermore, the interaction layer product has a lower density than that of the dispersed particles and significant volume expansion of the fuel should be expected as a result of its formation and growth. The ideal parameter to control the interaction layer formation and subsequent consumption of the matrix, based on the sensitivity studies reported here, appears to be the use of coarser particles.

HEU fuels currently in use have prescribed specifications on particle size distributions, even though the volume fraction of fuel in these designs is lower than that required for an LEU fuel design. For example, $\mathrm{UAl}_{\mathrm{x}}$ fuel typically contains a minimum of $75 \%$ dispersed particles between 44 and $149 \mu \mathrm{m}(-100+325$ mesh) and a maximum of $25 \%$ dispersed particles finer than $44 \mu \mathrm{m}$ (-325 mesh) [24]. $\mathrm{U}_{3} \mathrm{O}_{8}$ fuel typically has a maximum particle diameter of $88 \mu \mathrm{m}(-170$ mesh) with a maximum of $25 \%$ dispersed particles finer than $44 \mu \mathrm{m}$ (-325 mesh) [25]. As the volume fraction of dispersed phase in the matrix is increased, it would appear that the tolerable average particle size should also be increased or, at a minimum, the amount of fines $(<44 \mu \mathrm{m})$ allowed for fabrication should be reduced.

\section{CONCLUSIONS}

The Hsu equation appears to be the best model of those studied here to use for thermal conductivity determination of dispersion fuel systems. A simple model based on this equation that can also take into account formation of an interaction layer during either fabrication or irradiation as a function of particle size has been developed and validated against data available in literature. The thermal conductivity of the interaction layer does not appear to be the most important attribute in determining the overall conductivity of 
the dispersed fuel, but the best fit with experimental data was obtained when the interaction layer conductivity was assumed to be half that of the fuel particles. However, formation of the interaction layer and subsequent consumption of the matrix must be considered when calculating the effective thermal conductivity of the fuel meat. The interaction layer mainly consumes the matrix, although minor amounts of the original fuel particle may also be consumed. This is the only possible way to account for thermal conductivity degradation with increased interaction layer thickness. The effective thermal conductivity of the fuel can be influenced by the particle distribution. Coarser dispersed particles appear to preserve the thermal conductivity of the fuel better than finer particles when interaction layer formation is expected, mainly to minimize the amount of matrix that is consumed. While this may not significantly affect the operational temperature of some fuel designs, it is likely to mitigate swelling effects associated with excessive interaction layer formation. 


\section{ACKNOWLEDGEMENTS}

The authors would like to acknowledge Dr. Walter Luscher for his review of the manuscript and helpful discussion. This work was conducted at Pacific Northwest National Laboratory operated by Battelle for the United States Department of Energy under Contract DE-AC05-76RL01830. The work is in support of the National Nuclear Security Administration Global Threat Reduction Initiative.

This paper was prepared as an account of work sponsored by an agency of the United States Government. Neither the United States Government nor any agency thereof, nor Battelle Memorial Institute, nor any of their employees, makes any warranty, express or implied, or assumes any legal liability or responsibility for the accuracy, completeness, or usefulness of any information, apparatus, product, or process disclosed, or represents that its use would not infringe privately owned rights.

Reference herein to any specific commercial product, process, or service by trade name, trademark, manufacturer, or otherwise does not necessarily constitute or imply its endorsement, recommendation, or favoring by the United States Government or any agency thereof, or Battelle Memorial Institute. The views and opinions of authors expressed herein do not necessarily state or reflect those of the United States Government or any agency thereof. 


\section{REFERENCES}

1. D. Stahl, Fuels for Research and Test Reactors, Status Review: July 1982, Argonne National Laboratory Report ANL-83-5 (1982).

2. A. Glaser, About the Enrichment Limit for Research Reactor Conversion: Why $20 \%$ ? $27^{\text {th }}$ International Meeting on Reduced Enrichment for Research and Test Reactors, Boston, MA (2005).

3. International Atomic Energy Agency, Advanced Fuel Cycle and Reactor Concepts, Report of the International Fuel Cycle Evaluation (INFCE) Working Group 8, Vienna, Austria, STI/PUB/534 (1980).

4. A. Boltax, Behavior of Fissionable Material Under Irradiation, in: A.R. Kaufman (Ed.), Nuclear Reactor Fuel Elements, John Wiley \& Sons Inc., Hoboken, NJ, 1962, Chapter 9.

5. D.L. Porter and A. Ewh, Interaction Layer Characteristics in U-xMo Dispersion/Monolithic Fuels, Idaho National Laboratory Report INL/EXT-10-17972, Rev. 1, November 2010.

6. H.J. Ryu, Y.S. Kim, J.M. Park, H.T. Chae, and C.K. Kim, Performance Evaluation of U-Mo/Al Dispersion Fuel by Considering a Fuel-Matrix Interaction, Nuc. Eng. Tech. 40 (5) (2008) 409-418.

7. A.F. Williams, B.W. Leitch, and N. Wang, A Microstructural Model of the Thermal Conductivity of Dispersion Type Fuels with a Fuel Matrix Interaction Layer, Nuclear Engineering and Technology 45 (7) (2013) 839-846.

8. H.S. Carslaw and J.C. Jaeger, Conduction of Heat in Solids, $2^{\text {nd }}$ ed., Oxford University Press, New York, 1959, 421-428.

9. D.A.G. Bruggeman, Berechnung verschiedener physikalischer Konstanten von heterogenen Substanzen. I. Dielektrizitätskonstanten und Leitfähigkeiten der Mischkörper aus isotropen Substanzen, Ann. Phys. 416 (1935) 636-664.

10. W.Y. Hsu and T. Berzins, Percolation and effective-medium theories for perfluorinated ionomers and polymer composites, J. Polym. Sci. Polym. Phys. Ed. 23 (1985) 933-953.

11. D.E. Burkes, C.A. Papesch, A.P. Maddison, T. Hartmann, F.J. Rice, Thermo-physical properties of DU-10 wt\% Mo alloys, J. Nucl. Mater. 403 (2010) 160-166.

12. K.C. Mills, Recommended Values of Thermophysical Properties for Selected Commercial Alloys, Woodhead Publishing, United Kingdon (2002) 25. 
13. S.H. Lee, J.M. Park, and C.K. Kim, Thermophysical Properties of U-Mo/Al Alloy Dispersion Fuel Meats, Int. J. Thermophysics 28 (5) (2007) 1578-1594.

14. S.H. Lee, J.C. Kim, J.M. Park, C.K. Kim, and S.W. Kim, Effect of Heat Treatment on Thermal Conductivity of U-Mo/Al Alloy Dispersion Fuel, Int. J. Thermophysics 24 (5) (2003) 1355-1371.

15. B. Badrinarayan and J.W. Barlow, Prediction of the Thermal Conductivity of Beds Which Contain Polymer Coated Metal Particles, Solid Freeform Fabrication (SFF) Symposium (1990) 91-98.

16. D. Olander, Growth of the interaction layer around fuel particles in dispersion fuel, J. Nucl. Mater. 383 (2009) 201-208.

17. A. Jesse, G. Ondracek, and F. Thümmler, Preliminary Studies of the Fabrication of $\mathrm{UAl}_{4}$-Al Test-Plates by Powder-Metallurgical Techniques, Powder Metall. 14 (28) (1971) pp. 289-297.

18. T.I. Jones, K.N. Street, J.A. Scoberg, and J. Baird, Relation between microstructure and thermal conductivity in Aluminum-Uranium alloys, Can. Metall. Quarterly 2 (1) (1963) pp. 53-71

19. C.R. Clark, B.R. Muntifering, J.-F. Jue, Production and Characterization of Atomized U-Mo Powder by the Rotating Electrode Process, Proceedings of the RERTR-2007 International Meeting on Reduced Enrichment for Research and Test Reactors, Prague, Czech Republic (2007).

20. Y.S. Kim, G.L. Hofman, H.J. Ryu, and S.L. Hayes, Irradiation-Enhanced Interdiffusion in the Diffusion Zone of U-Mo Dispersion Fuel in Al, J. Phase Equil. Diff. 27 (6) (2006) 614-621.

21. S.L. Hayes, M.K. Meyer, G.L. Hofman, and J.L. Snelgrove, U-Mo/Al Dispersion Fuel Modeling, Technical Meeting on the Development of High Density U-Mo Dispersion Fuels, Vienna, Austria, June 23-25, 2003.

22. Y.S. Kim and G.L. Hofman, Improved Performance of U-Mo Dispersion Fuel by Si Addition in Al Matrix, Argonne National Laboratory Report ANL/RERTR/TM-1124, June 2011.

23. P.G. Medvedev, Effect of In-Pile Degradation of the Meat Thermal Conductivity on the Maximum Temperature of the Plate-Type U-Mo Dispersion Fuels, $31^{\text {st }}$ International Meeting on Reduced Enrichment for Research and Test Reactors, Beijing, China, November 1-5, 2009. 
24. J.M. Beeston, R.R. Hobbins, G.W. Gibson, and W.C. Francis, Development and Irradiation Performance of Uranium Aluminide Fuels in Test Reactors, Nuc. Tech. 49 (1980) 136-149.

25. G.L. Copeland and M.M. Martin, Development of High-Uranium-Loaded $\mathrm{U}_{3} \mathrm{O}_{8}-\mathrm{Al}$ Fuel Plates, Nuc. Tech. 56 (1982) 547-552. 


\section{FIGURE CAPTIONS}

Figure 1. Scatter plot comparing measured composite thermal conductivity to the predicted composite thermal conductivity using the Maxwell, Bruggeman, and Hsu models.

Figure 2. Thermal conductivity of a composite consisting of 30 vol\% U-10Mo $60 \mu \mathrm{m}$ diameter (average) particles dispersed in an AA 1060 matrix as a function of temperature. The different samples have been subjected to thermal heat treatments to induce interaction layer formation of varying thickness $[13,14]$.

Figure 3. Thermal conductivity of a composite containing 30 vol\% U-10Mo dispersed in an aluminum matrix calculated assuming the $3 \mu \mathrm{m}$ interaction layer consumes fuel particles only, the aluminum matrix only, or equal amounts of fuel and matrix as a function of temperature. The calculations are compared to experimental measurements (sample U10M-5) reported by Lee et al. [14].

Figure 4. Thermal conductivity of a composite containing 30 vol\% U-10Mo dispersed in an aluminum matrix calculated assuming the $3 \mu \mathrm{m}$ interaction layer has a thermal conductivity half the value of the fuel particle, equal to the fuel particle, and twice the value of the fuel particle as a function of temperature. The calculations are compared to experimental measurements reported by Lee et al. [14].

Figure 5. Thermal conductivity of a composite containing 30 vol\% U-10Mo dispersed in an aluminum matrix calculated with three different fuel particle diameters as a function of temperature. The calculations are compared to experimental measurements reported by Lee et al. [14].

Figure 6. Scatter plot comparing measured composite thermal conductivity to the predicted composite thermal conductivity using Equations 3 and 5 for different volume fractions of fuel and interaction layer thicknesses. The experimental measurements were reported by Lee et al. [14]. The dashed lines in the figure represent deviation of $\pm 10 \%$. 


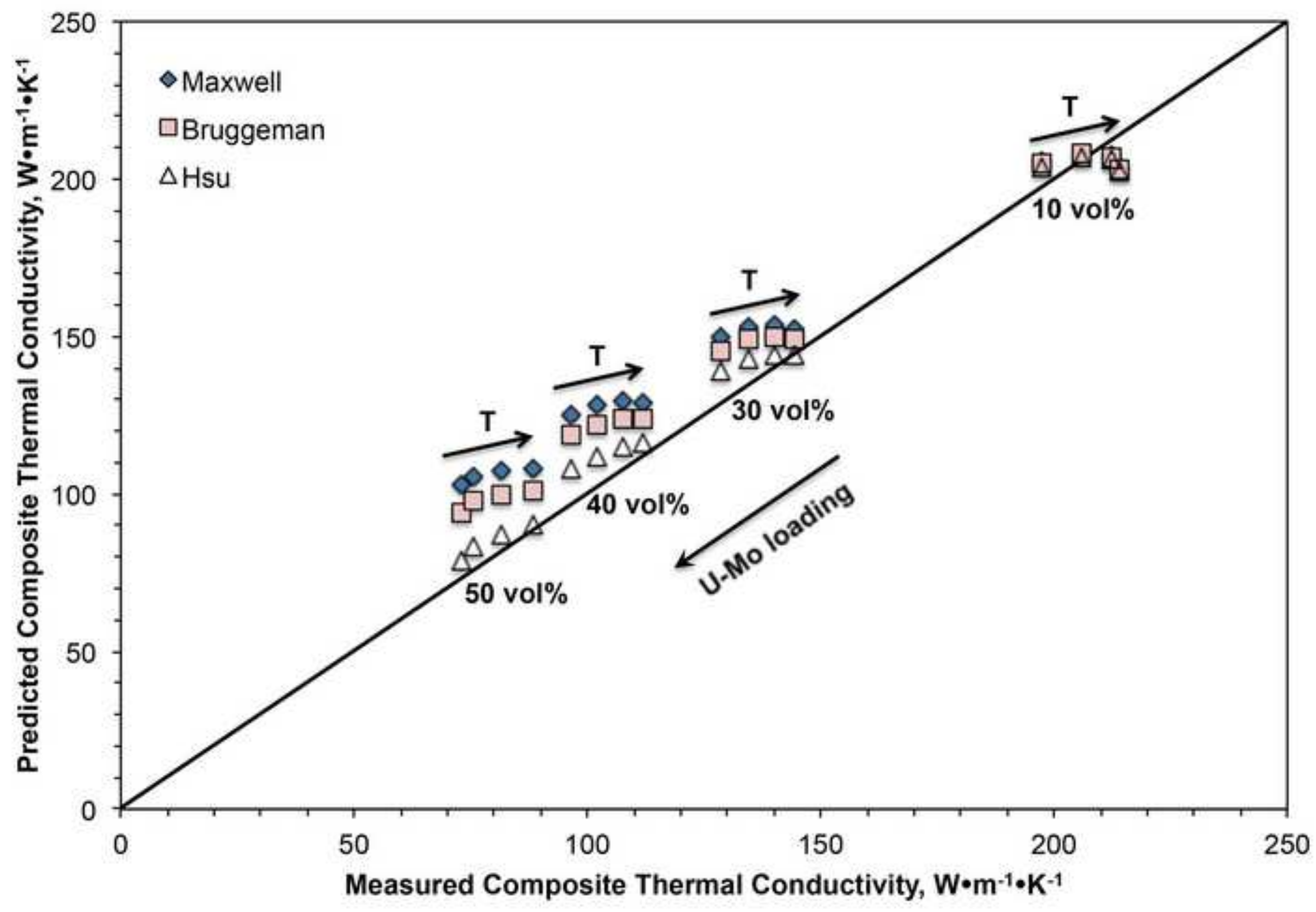




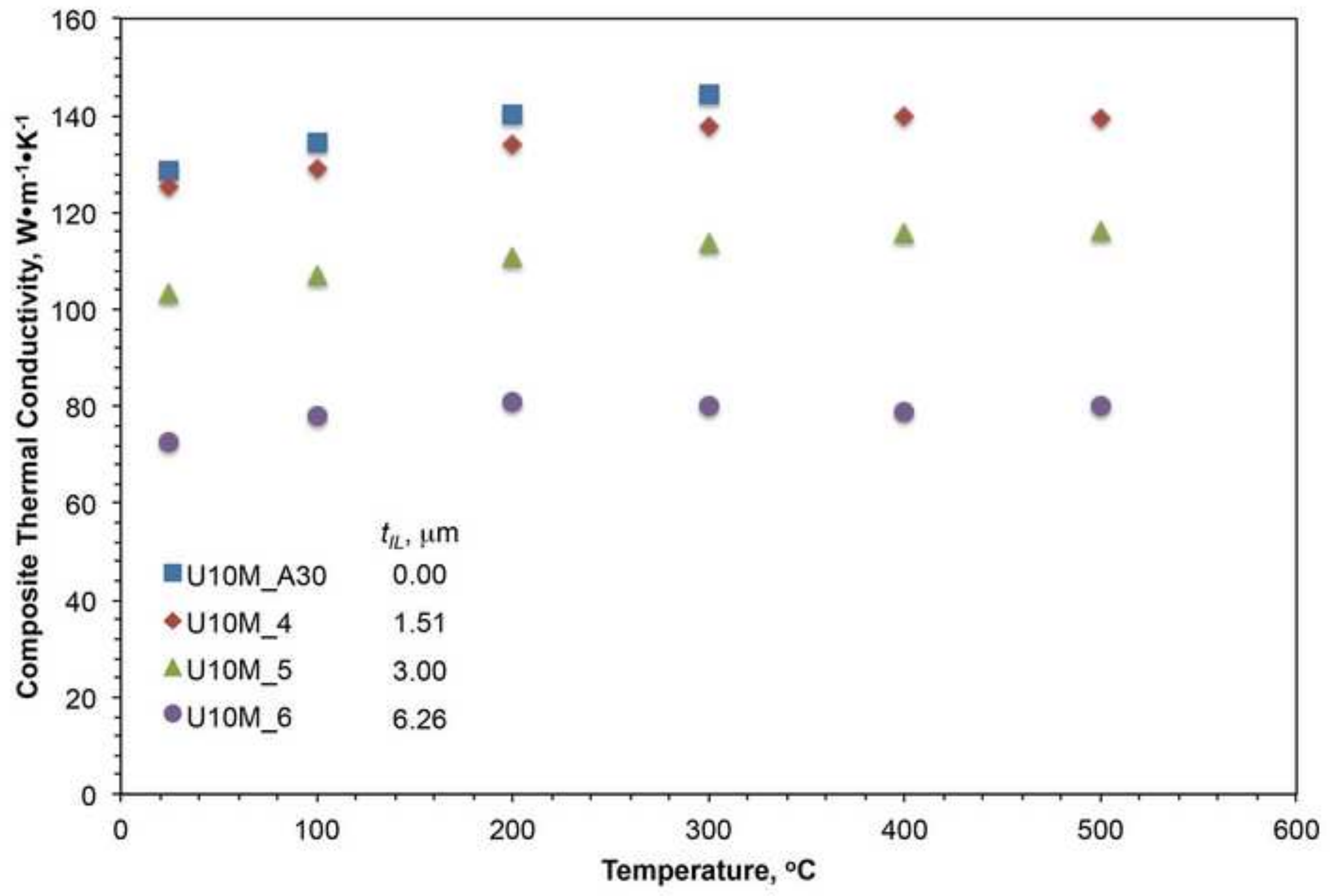




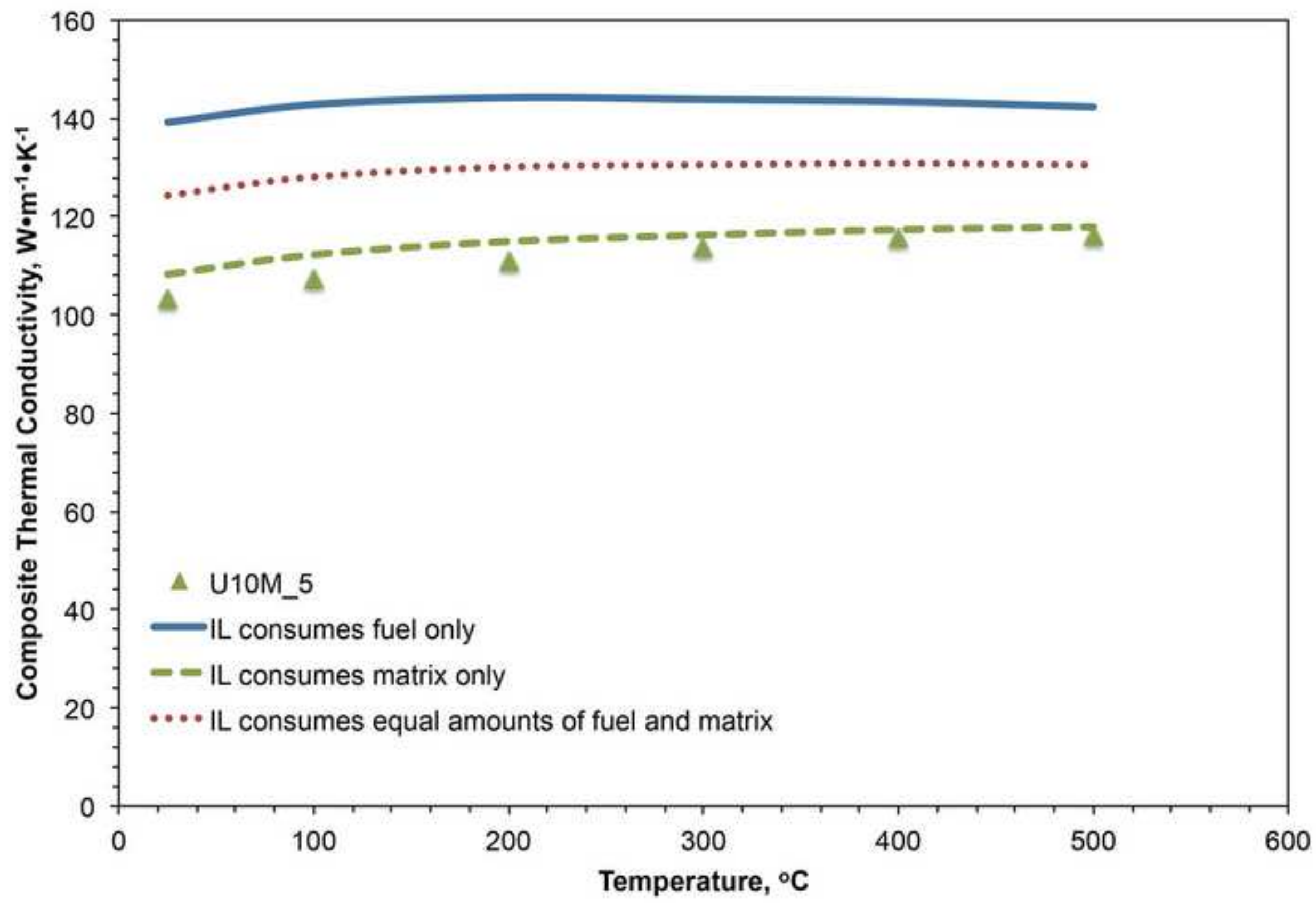




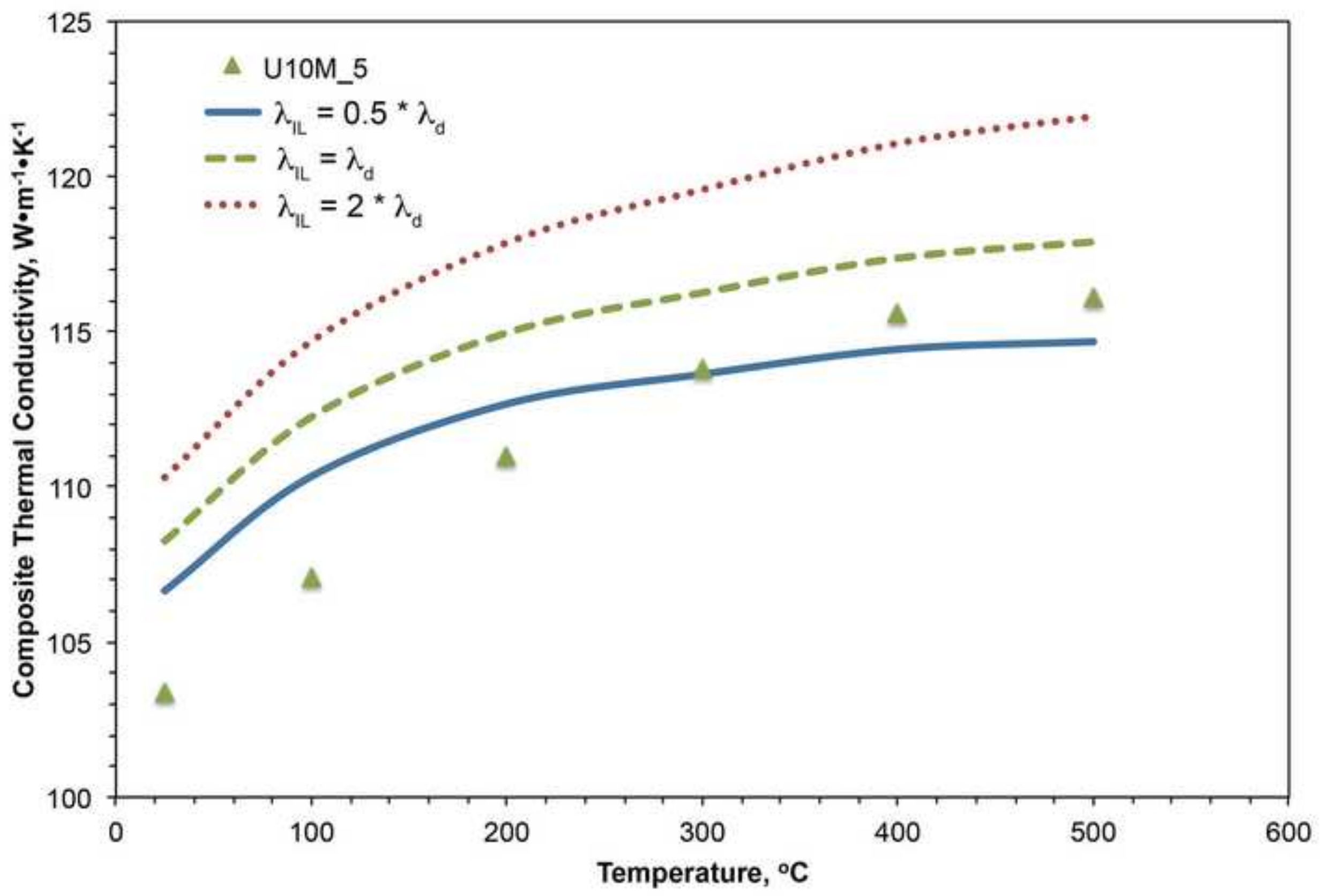




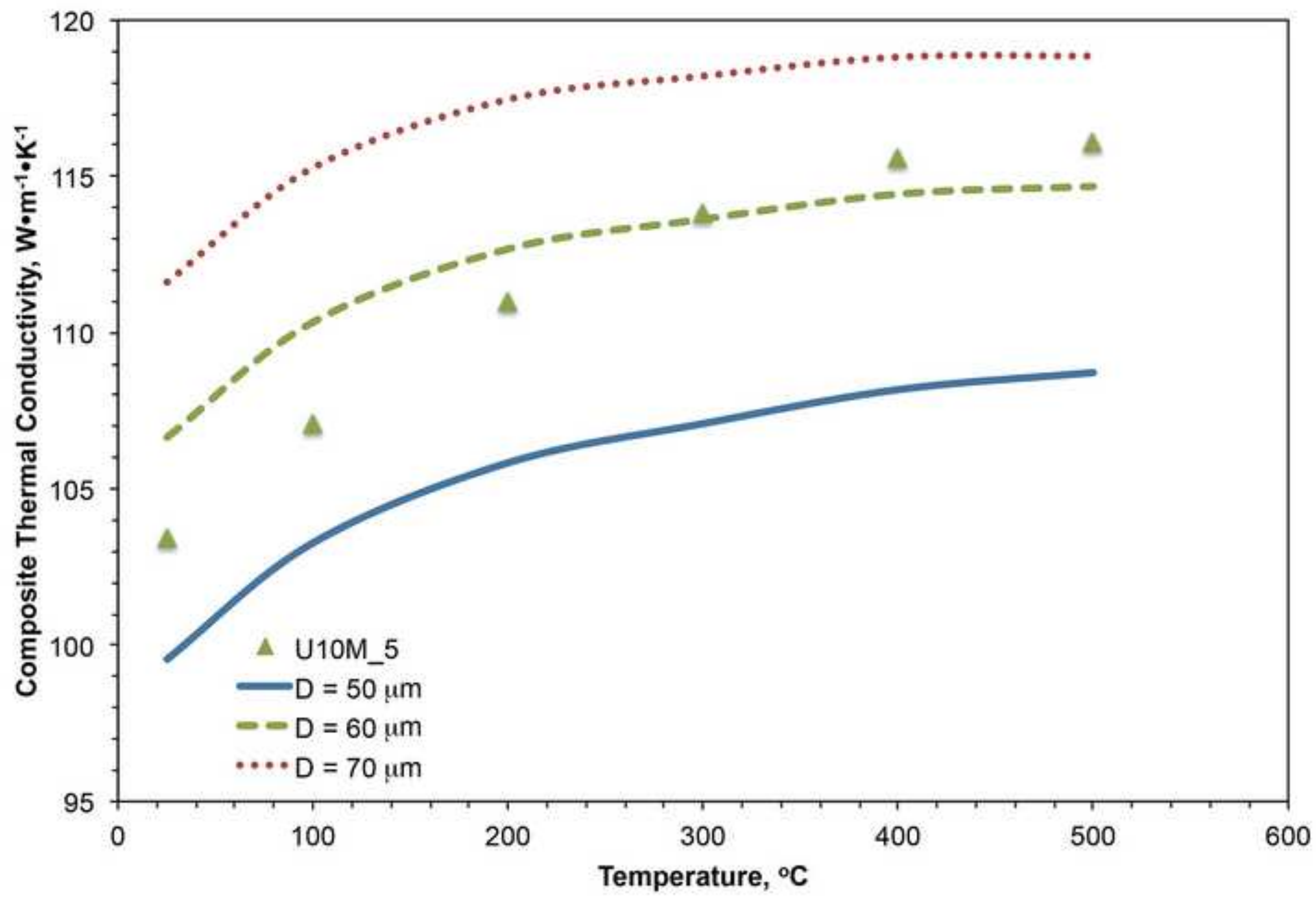




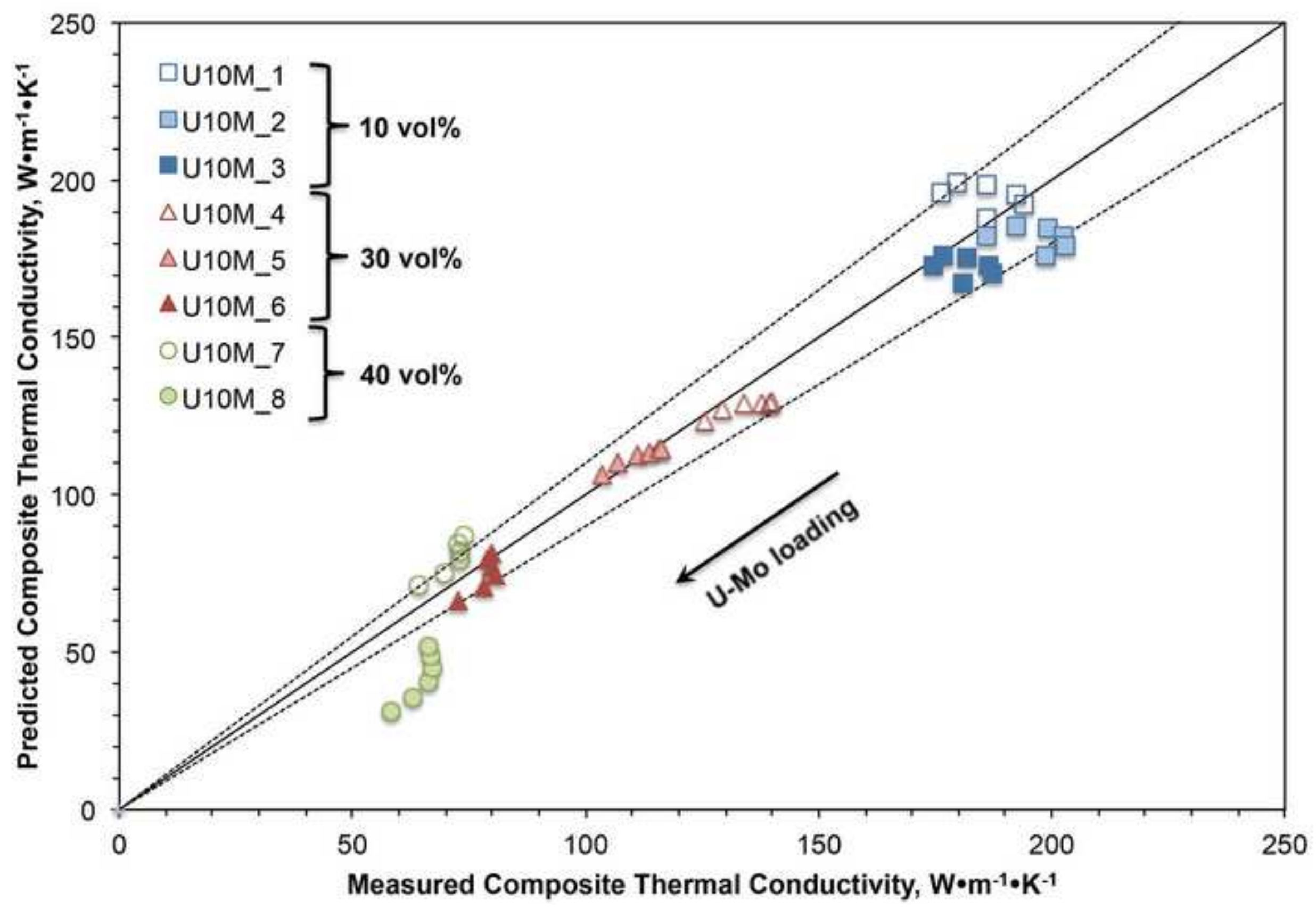

